\title{
Molecular dynamics study on the Li diffusion mechanism and delithiation process of $\mathrm{Li}_{2} \mathrm{MnO}_{3}$
}

\author{
Yang Huanga ${ }^{\mathrm{a}^{*}}, \quad$ Long Liu ${ }^{\mathrm{b}}, \quad$ Min $\mathrm{Gao}^{\mathrm{a}^{*}}$ \\ a. China Spallation Neutron Source (CSNS), Institute of High Energy Physics (IHEP), \\ China Academy of Science (CAS), Dongguan, 523803, China \\ b. Shandong Analysis and Test Center, Qilu University of Technology \\ (Shandong Academy of Sciences), Jinan 250014, China \\ * Yang Huang, E-mail: huangyang@ihep.ac.cn \\ * Min Gao, E-mail: gao.1.min@gmail.com
}

\begin{abstract}
$\mathrm{Li}_{2} \mathrm{MnO}_{3}$ is critical component in the well-studied Li-excess cathode materials $\mathrm{xLi}_{2} \mathrm{MnO}_{3} \cdot(1-\mathrm{x}) \mathrm{LiMO}_{2}$ for achieving high lithium storage capacity. In this article, the diffusion of $\mathrm{Li}$ ions in $\mathrm{Li}_{2} \mathrm{MnO}_{3}$ is studied using molecular dynamics (MD) simulation with well-behaved empirical force fields obtained by fitting against the crystal structure from experiment and phonons calculated using Density Function Theory (DFT). We have found two possible tetrahedral hopping channels, $0-\mathrm{TM}$ and $1-\mathrm{TM}\left(\mathrm{Mn}^{4+}\right)$ channel, which are differentiated by the face sharing octahedral cations. Simulation results show that the $0-\mathrm{TM}$ channel is active for Li hopping, while 1-TM( $\left.\mathrm{Mn}^{4+}\right)$ channel is inactive. During the delithiation process, the Li ions in the transition metal (TM) layer are firstly removed, then those in the Li layer. However, the Li ions will be trapped in the tetrahedral 0-TM channels as long as the four face sharing octahedral sites are cleared. $\mathrm{Up}$ to $\mathrm{x}=1.0$ for $\mathrm{Li}_{2-\mathrm{x}} \mathrm{MnO}_{3}$, almost all the $\mathrm{Li}$ ions are located at the tetrahedral sites, forming a regular array along a axis. The de-intercalation of tetrahedral $\mathrm{Li}$ ions requires a high voltage ( $>5.2 \mathrm{~V}$ vs. $\mathrm{Li} / \mathrm{Li}+)$, limiting the practical capacities measured in lab. The diffusion of $\mathrm{Mn}$ ions into the Li layer is observed in a deeper delithiated structure $(\mathrm{x}=1.2$ for $\mathrm{Li}_{2-\mathrm{x}} \mathrm{MnO}_{3}$ ), indicating an initial phase transformation to a spinel-like structure. However, the Mn ions are mainly trapped in the tetrahedral sites in the Li layer, instead of the octahedral sites in spinel-like structure. A few of Mn ions diffusing into the octahedral sites in Li layers have no face sharing tetrahedral $\mathrm{Li}$ ions, revealing a further Li de-intercalation is imperative for the complete phase transformation. Our model is not stable for $\mathrm{x} \geq 1.4$ in $\mathrm{Li}_{2-\mathrm{x}} \mathrm{MnO}_{3}$. Other charge compensation mechanism should be considered in this high delithiation stage, eg. oxygen release.
\end{abstract}

Keywords: $\mathrm{Li}_{2} \mathrm{MnO}_{3}$; Molecular dynamics; diffusion; delithiation 


\section{Introduction}

Lithium-ion batteries are considered to be one of the best candidates for hybrid electric vehicle and plug-in hybrid electric vehicle applications, because of their high energy density, high power density, long service life and environmental friendliness. Cathode materials play an important role on determining the performance and safety of lithium-ion batteries. At present, layered transition metal oxides $\left(\mathrm{LiCoO}_{2}\right)$ [1], spinels $\left(\mathrm{LiMn}_{2} \mathrm{O}_{4}\right)$ [2], and olivines $\left(\mathrm{LiFePO}_{4}\right)$ [3] are the mainly used cathode materials in the commercial lithium-ion batteries. The surface reactivity and instability of delithiated $\mathrm{Li}_{\mathrm{x}} \mathrm{CoO}_{2}$ limit the practical capacity of $\mathrm{LiCoO}_{2}$ electrodes to approximately $140 \mathrm{mAh}$ $\mathrm{g}^{-1}$, which corresponds to about $50 \%$ of its theoretical value $\left(273 \mathrm{mAh} \mathrm{g}^{-1}\right)$ [4]. On the other hand, though the $4 \mathrm{~V}$ spinel $\mathrm{LiMn}_{2} \mathrm{O}_{4}$ and $3.4 \mathrm{~V}$ olivine $\mathrm{LiFePO}_{4}$ have drawn lots of attention due to their excellent cyclic performance, environmentally friendly nature, and low cost. They both have relative low energy densities due to the low capacity for the former and the low operating voltage for the later [5]. Therefore, great efforts have been devoted to explore alternative cathodes in order to improve the energy density of large-scale rechargeable lithium-ion batteries (LIB).

In the past decades, a type of layered Li-excess cathode materials with composite structure in which a layered $\mathrm{Li}_{2} \mathrm{MnO}_{3}$ component is structurally integrated with a layered $\mathrm{LiMO}_{2}$ component was proposed [6-9]. Nearly 1 mol of lithium can be extracted from this kind of Li-rich Mn-based layered material, corresponding to capacities of 250-300 $\mathrm{mAhg}^{-1}$, much higher than those in the commercial application. The layered $\mathrm{Li}_{2} \mathrm{MnO}_{3}$ is a critical component in the Li-excess materials and its specific capacity could reach an ideal $459 \mathrm{mAhg}^{-1}$. Characteristic potential profiles with a flat and wide plateau at $\sim 4.5 \mathrm{~V}$ in the first charging are observed in the first charge/discharge cycle of $\mathrm{Li}_{2} \mathrm{MnO}_{3}$, which is believed to be responsible for the high-voltage (4.4-5 V) of Li-excess materials [10]. Hence, further studies on one of the end members of the composites, $\mathrm{Li}_{2} \mathrm{MnO}_{3}$, could shed valuable insights on the electrochemical behaviour, chemical composition, structural stability and cycling deficiency of the layered Liexcess materials.

In past few years, much work has been done to study the properties of $\mathrm{Li}_{2} \mathrm{MnO}_{3}$, both in laboratory and theoretical calculations. $\mathrm{In}_{2} \mathrm{innO}_{3}$, it is generally believed that $\mathrm{Mn}$ can not be oxidised beyond +4 in an octahedral oxygen environment. Theoretically, $\mathrm{Li}_{2} \mathrm{MnO}_{3}$ is electrochemically inactive. However, experimental results show that the material is in fact electrochemically active, and the charge/discharge capacities depend strongly on synthesis conditions. So the experimental researchers pay much attention on explaining the source of electrochemical activities of $\mathrm{Li}_{2} \mathrm{MnO}_{3}$. Many proposals have been proposed, such as the irreversible loss of oxygen from the surface $[11,12,13,14]$, partially oxidised oxygen anions $[10,15,16]$, surface reaction through electrode/electrolyte reduction and/or hydrogen exchange[17,18,19]. Clearly, the origin of electrochemical activity is still in debate and more work should be done to get a better understanding. For the theoretical studies on $\mathrm{Li}_{2} \mathrm{MnO}_{3}$, only several DFT works have been reported $[10,14,15,16]$. In these works, the authors discussed the charge 
compensation mechanism, the structure evolution, the operating voltage and the kinetics of Li diffusion.

It is well known that during the charging/ discharging process of $\mathrm{LIB}, \mathrm{Li}$ ions will move circularly between the cathodes and anodes. So the transporting mechanism of Li ions is very important for the final performance of LIB. Using molecular dynamics, one can track the Li ion movement in the materials theoretically. It helps to a get better perceiving about the details of Li transporting in materials. However, classical molecular simulations suffer from the limitations in available classical interatomic force fields (or, interatomic potentials). Due to the complex combination of chemical species as well as inter molecular interactions, parametrization of interatomic force fields is challenging, thereby limiting applications of classical MD in exploring the large scale structural properties of materials. In this work, we developed a force field for $\mathrm{Li}_{2} \mathrm{MnO}_{3}$ based on a standard model from the work of Alfonso Pedone et al [20], by fitting against the crystal structure and the phonon spectrum. Then we simulated the stoichiometric and delithiated $\mathrm{Li}_{2} \mathrm{MnO}_{3}$ by MD with our force field parameters. The macro diffusion directions and the micro hopping paths of $\mathrm{Li}$ ions, the delithiation mechanism, and the possible phase transformation path are discussed based on the MD simulation. Some of the results accord with those predicted by DFT calculations or measured by experiments, proving the rationality of our force field. In addition, a new delithiation mechanism involving the tetrahedral $\mathrm{Li}$ and a new phase transformation way involving the tetrahedral $\mathrm{Mn}$ is proposed. We believe that our way of improving the initially rough force field is universal and can be applied to other LIB materials in which the ion transport properties are the research emphasis.

\section{Methodology}

\section{1. $\mathrm{Li}_{2} \mathrm{MnO}_{3}$ Structure}

The crystal structure of $\mathrm{Li}_{2} \mathrm{MnO}_{3}$ is illustrated in Figure 1. The space group of this material is $\mathrm{C} 2 / \mathrm{m}$. It resembles other layered materials $\mathrm{LiMO}_{2}(\mathrm{M}=\mathrm{Co}, \mathrm{Ni}, \mathrm{Mn})$. The $\mathrm{Li}$ layer, O layer and transition metal (TM) layer are stacked layer by layer consecutively with ABC form (O3-type). Furthermore, excess of Li ions enter Mn layer and replace some of them. So the chemical formula can be rearranged as $\mathrm{Li}\left(\mathrm{Li}_{1 / 3} \mathrm{Mn}_{2 / 3}\right) \mathrm{O}_{2}$. As a result, the symmetry of $\mathrm{LiMO}_{2}$ is broken and the $\mathrm{Li}$ sites can be divided into $\mathrm{Li}_{2 \mathrm{~b}}$ (in the TM layer), $\mathrm{Li}_{2 \mathrm{c}}$ and $\mathrm{Li}_{4 \mathrm{~h}}$ (in the $\mathrm{Li}$ layer). Figure 1 also shows the arrangement of ions in the TM layer and in the Li layer. Each $2 \mathrm{~b}$ site is coordinated by six $\mathrm{Mn}$ sites in the TM layer, each $2 \mathrm{c}$ site is coordinated by six $4 \mathrm{~h}$ sites in the Li layer and each $4 \mathrm{~h}$ site is coordinated by three $4 \mathrm{~h}$ sites and three $2 \mathrm{c}$ sites.

\subsection{Potential Model}

In this article, the Morse function is used to model the interaction between ions. There are three terms contributed to the potential as shown in Equation (1):

$$
\mathrm{U}(r)=\frac{z_{i} z_{j} e^{2}}{r}+D_{i j}\left[\left\{1-e^{-a_{i j} \cdot\left(r-r_{i j}\right)}\right\}^{2}-1\right]+\frac{C_{i j}}{r^{12}}
$$

in which the first term is the long-range coulomb potential, $\mathrm{z}_{\mathrm{i}}$ and $\mathrm{z}_{\mathrm{j}}$ are ionic charges, $r$ is the distance between two atoms. The second term is the short-range Morse function, 
The last term $\mathrm{C} / \mathrm{r}^{12}$ represents the repulsive interaction.

The Morse function is usually used in modelling bonded interactions in covalent systems (e.g., the hydroxide ion in ionic systems) in which the Coulomb term is subtracted. The physical meaning of the different quantities is well defined: $\mathrm{D}_{\mathrm{ij}}$ is the bond dissociation energy, $\mathrm{a}_{\mathrm{ij}}$ is a function of the slope of the potential energy well, and $\mathrm{r}_{\mathrm{ij}}$ is the equilibrium bond distance.

The repulsive term, $\mathrm{C} / \mathrm{r}^{12}$, is necessary to represent the interaction at high temperature and high pressure. In our work, the repulsive interaction is not considered since we are just interesting in the properties at the normal pressures and temperatures below1000K.

\subsection{Interatomic Potential Derivation}

The empirical fitting method implemented in the GULP package [21] was used to derive the interatomic potential parameters. In our strategy, the parameters are derived to reproduce the experimental crystal structures (lattice parameters and atomic positions) and phonon frequencies.

The conventional fitting procedure consists of the following steps:

(1) Fit the interatomic potential parameters to the experimental crystal structure [22]. The initial guess for the potential parameters is from the work of Alfonso Pedone et al. [20]. Their model is established for binary oxides which covers the most of transition metal (TM) /lithium-oxygen interactions. So it is convenient to transplant them to the Li-TM-O system of cathode materials. For the $\mathrm{Li}_{2} \mathrm{MnO}_{3}$, we optimized the initial potential parameters (the ionic charges are kept constant, only $\mathrm{D}_{\mathrm{ij}}$, $\mathrm{a}_{\mathrm{ij}}$ and $\mathrm{r}_{\mathrm{ij}}$ are fitted) and relaxed the structure with them. The relaxed structure is compared with the experimentally measured ones. Typically we expect a good potential model to have an accuracy for the crystal structure of up to $2 \%$

(2) Calculate the phonon frequencies of $\mathrm{Li}_{2} \mathrm{MnO}_{3}$ with the optimized potential parameters. Check if all the phonons have the real and positive frequencies. Since $\mathrm{Li}_{2} \mathrm{MnO}_{3}$ exist in nature as a stable phase, any imaginary frequency calculated by our potential parameters suggest a further optimization is needed for a better representation of the shape of the energy surface.

(3) As a more rigorous calibration, we compared the phonon frequencies calculated with our potential parameters and by DFT calculation accomplished in the PHONOPY package [23]. The potential parameters should be further optimized to give a better fitting of DFT results, especially in the low frequency range.

The final potential parameters are listed in table 1. Table 2 lists the relaxed unit-cell structure and the experimental structure. The maximum error is $-1.93 \%$, proving the reliability of our model to describe the energy surface at the local minimum of $\mathrm{Li}_{2} \mathrm{MnO}_{3}$.

Figure 2 shows the phonon frequencies calculated with our potential model and with DFT calculation. No imaginary frequencies are observed and a relatively high match between the phonon frequencies (especially in the low frequency range) calculated with the two method is obtained. It proves that our potential model is suitable for the simulation of thermal vibrations which control the Li transport in the system.

\subsection{Molecular dynamics simulation details}

The DL_POLY (Version 4.07) [24] was used to perform all the MD simulations. Periodic boundary condition were applied in all directions. Atomic motions and 
Coulombic interactions were calculated by the Verlet algorithm [25] and Ewald method [26] respectively. The time step was $1 \mathrm{fs}$. Nose-Hoover thermostat was used to regulate the system's temperature at specific temperatures [27, 28].

A set of configurations with different percentage of $\mathrm{Li}$ ions $\left(\mathrm{Li}_{\mathrm{x}} \mathrm{MnO}_{3} 1<\mathrm{x}<2\right)$ are created from a $10 \times 6 \times 9$ supercell of the $\mathrm{Li}_{2} \mathrm{MnO}_{3}$ unit cell, which contains $4320 \mathrm{Li}$ ions, $2160 \mathrm{Mn}$ ions and $6480 \mathrm{O}$ ions. $\mathrm{Li}$ ions are removed randomly to create vacancies. The charge of the removed $\mathrm{Li}$ is compensated by increasing the valence state of $\mathrm{O}$ anions to keep the system neural. This strategy is verified by the DFT calculation $[10,15,16]$ and it can keep the structural stability of $\mathrm{Li}_{\mathrm{x}} \mathrm{MnO}_{3}$ in a large Li removal range.

Table 1: The potential parameters of Morse function for $\mathrm{Li}_{2} \mathrm{MnO}_{3}$ system.

\begin{tabular}{|c|c|c|c|}
\hline Interaction & $\mathrm{D}_{\mathrm{ij}}(\mathrm{ev})$ & $\mathrm{a}_{\mathrm{ij}}\left(\AA^{-2}\right)$ & $\mathrm{R}_{\mathrm{ij}}(\AA)$ \\
\hline $\mathrm{Li}^{+0.6}-\mathrm{O}^{-1.2}$ & 0.001114 & 3.429506 & 2.621360 \\
\hline $\mathrm{Mn}^{+2.4}-\mathrm{O}^{-1.2}$ & 0.029658 & 2.607543 & 2.452075 \\
\hline $\mathrm{O}^{-1.2}-\mathrm{O}^{-1.2}$ & 0.042395 & 2.379316 & 3.148701 \\
\hline
\end{tabular}

Table 2: The optimized unit-cell structure and the experimental structure.

\begin{tabular}{|c|c|c|c|c|}
\hline & $\begin{array}{c}\text { Experimental } \\
\text { value }\end{array}$ & $\begin{array}{c}\text { Optimized } \\
\text { value }\end{array}$ & Difference & $\begin{array}{c}\text { Error } \\
(\%)\end{array}$ \\
\hline Volume $\left(\AA^{3}\right)$ & 199.7725 & 195.9116 & -3.8609 & -1.93 \\
\hline $\mathrm{a}(\AA)$ & 4.9370 & 4.9252 & -0.0118 & -0.24 \\
\hline $\mathrm{b}(\AA)$ & 8.5320 & 8.5206 & -0.0114 & -0.13 \\
\hline $\mathrm{c}(\AA)$ & 5.0300 & 4.9467 & -0.0833 & -1.66 \\
\hline$\beta($ degree $)$ & 109.4600 & 109.3096 & -0.1504 & -0.14 \\
\hline $\mathrm{Li}_{4 \mathrm{~h}}(\mathrm{y})$ & 0.6606 & 0.6477 & 0.0129 & 1.95 \\
\hline $\mathrm{Mn}_{4 \mathrm{~g}}(\mathrm{y})$ & 0.1671 & 0.1676 & 0.0005 & 0.32 \\
\hline $\mathrm{O}_{4 \mathrm{i}}(\mathrm{x})$ & 0.2189 & 0.2176 & 0.0013 & 0.60 \\
\hline $\mathrm{O}_{4 \mathrm{i}}(\mathrm{z})$ & 0.2273 & 0.2232 & 0.0041 & 1.81 \\
\hline $\mathrm{O}_{8 \mathrm{j}}(\mathrm{x})$ & 0.2540 & 0.2516 & 0.0024 & 0.96 \\
\hline $\mathrm{O}_{8 \mathrm{j}}(\mathrm{y})$ & 0.3212 & 0.3221 & 0.0009 & 0.29 \\
\hline $\mathrm{O}_{8 \mathrm{j}}(\mathrm{z})$ & 0.2233 & 0.2213 & 0.0020 & 0.89 \\
\hline
\end{tabular}

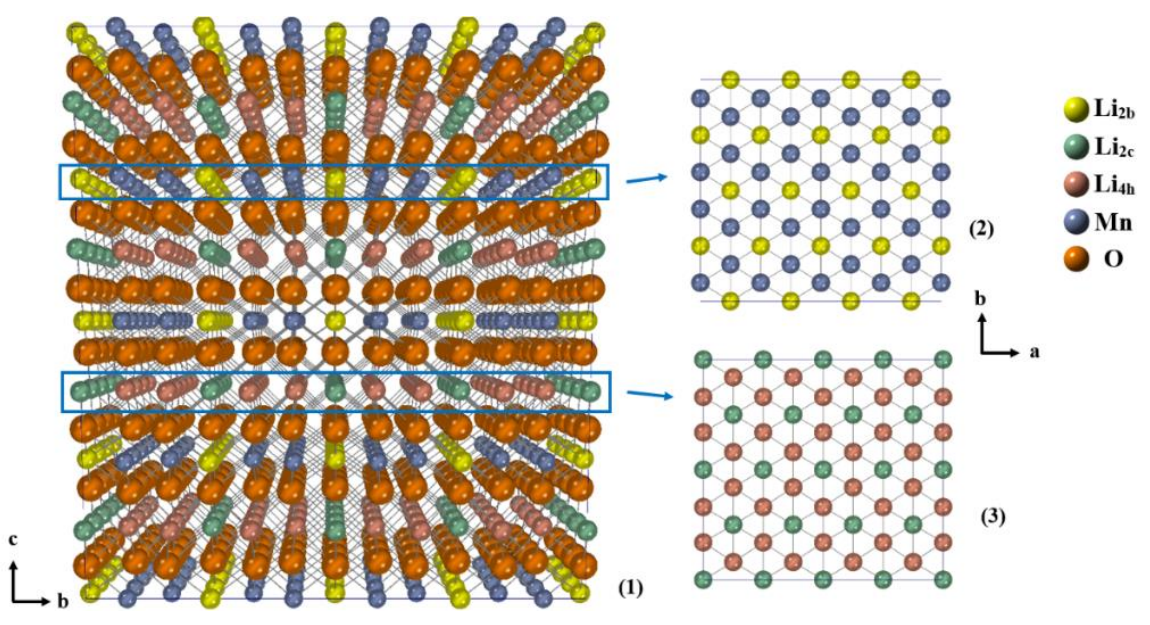

Figure 1. (1) A sketch of the crystal structure of $\mathrm{Li}_{2} \mathrm{MnO}_{3}$ (2) The atom arrangement in the TM layer (viewed from (001) direction) (3) the atom arrangement in the Li layer (viewed from (001) direction) 

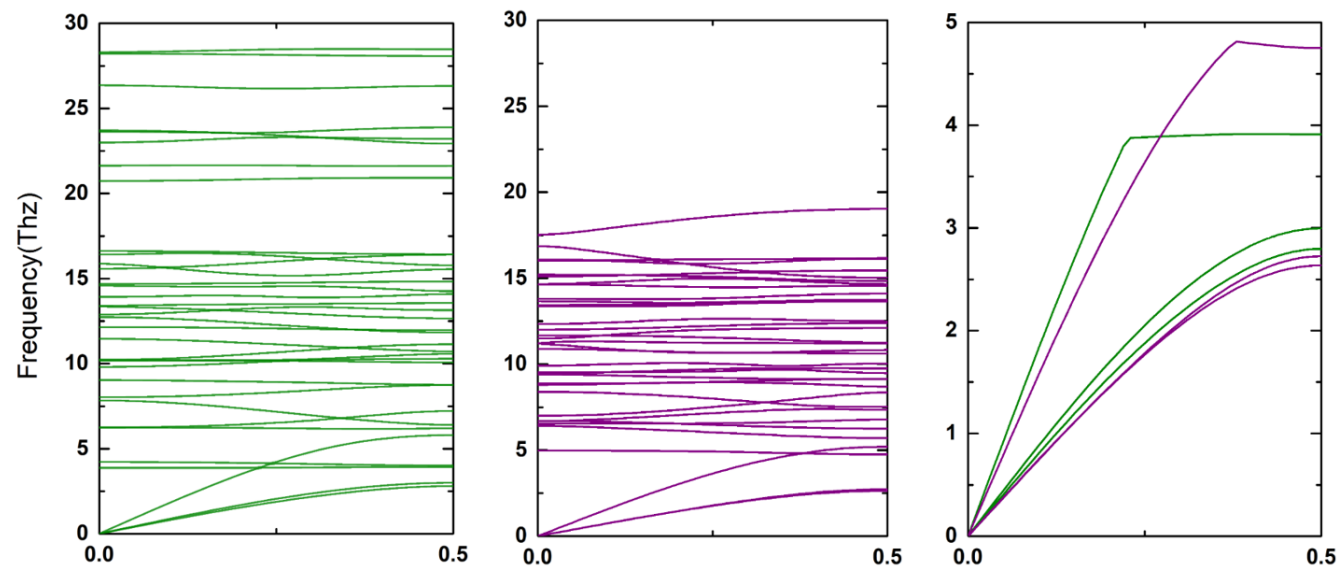

Reduced wave vector

Figure 2. The phonon spectrum calculated along the wave vectors $[0,0,0]$ to $[0,0,0.5]$ with our potential mode (in green color) and with DFT method (in purple color). An enlargement picture of the three acoustic branches which shows a high accordance is also displaced.

\section{Results}

\subsection{The macro diffusion of $\mathrm{Li}$}

It is well known that the LIB is charged/discharged through Li ions intercalation/deintercalation in the positive and negative anodes. So the diffusion of $\mathrm{Li}$ is crucial for the operational performance of LIB, especially the rate of charge/discharge.

Firstly, we investigated the macro diffusion of $\mathrm{Li}$ in stoichiometric $\mathrm{Li}_{2} \mathrm{MnO}_{3}$ by calculating the Mean Square Displacement (MSD) of Li ions along the directions of a, $\mathrm{b}$ and $\mathrm{c}$ axes. Figure 3 shows the results simulated at 1000K in NPT ensemble. It is obvious that Li can diffuse along all the three axes. This result is constituent with those obtained by DFT calculation [15].

We have further studied the individual diffusions of Li ions at $2 b, 2 c$ and 4 h sites more closely. The sub-plots (2), (3), (4) of figure 3 show the MSD along the three axes of $\mathrm{Li}_{2 \mathrm{~b}}, \mathrm{Li}_{2 \mathrm{c}}$ and $\mathrm{Li}_{4 \mathrm{~h}}$ respectively. $\mathrm{Li}_{2 \mathrm{~b}}$ mainly diffuse along $\mathrm{c}$ axis. This is expected considering the local chemical environments of $2 b$ sites in the TM layer. Each $\mathrm{Li}_{2 b}$ is coordinated by six $\mathrm{Mn}-\mathrm{O}$ octahedrons in the ab plane. So if $\mathrm{a} \mathrm{Li}_{2 b}$ ion would migrate to the nearest $\mathrm{Li}_{2 b}$ vacancy site, it should cross the $\mathrm{Mn}$ coordinated layer. The long migrating path hinders the diffusion of $\mathrm{Li}_{2 \mathrm{~b}}$ in the TM layer. Also, the slow increase of $\mathrm{Li}_{2 b}$ MSD along $\mathrm{a}$ and $\mathrm{b}$ axes indicate they may enter the Li layer along $\mathrm{c}$ axis and diffuse along $a$ and $b$ axes there.

Checking the diffusion of the $\mathrm{Li}_{2 \mathrm{c}}$ and $\mathrm{Li}_{4 \mathrm{~h}}$ in the $\mathrm{Li}$ layer, some different characters are observed. The increase of MSD along c axis indicates that both $\mathrm{Li}_{2 \mathrm{c}}$ and $\mathrm{Li}_{4 \mathrm{~h}}$ can diffuse along $\mathrm{c}$ axis. So the diffusion into Li layers of $\mathrm{Li}_{2 b}$ can be compensated by the diffusion into $\mathrm{TM}$ layers of $\mathrm{Li}_{2 \mathrm{c}}$ and $\mathrm{Li}_{4 \mathrm{~h}}$, resulting the overall three-dimensional diffusion of $\mathrm{Li}$ ions in the system. A further analysis of MSD shows that the diffusion rate of $\mathrm{Li}_{4 \mathrm{~h}}$ along $\mathrm{a}$ and $\mathrm{b}$ axes is uniform, while $\mathrm{Li}_{2 \mathrm{c}}$ diffuse along a axis more intentionally. It indicates that though $\mathrm{Li}_{4 \mathrm{~h}}$ and $\mathrm{Li}_{2 \mathrm{c}}$ sites have the same local coordinating 
environment within the Li inter-slab, the farther TM layer can influence the movement of $\mathrm{Li}_{2 \mathrm{c}}$ and $\mathrm{Li}$ 4h. This point will be investigated further by analyzing the micro hopping mechanism in the next section.

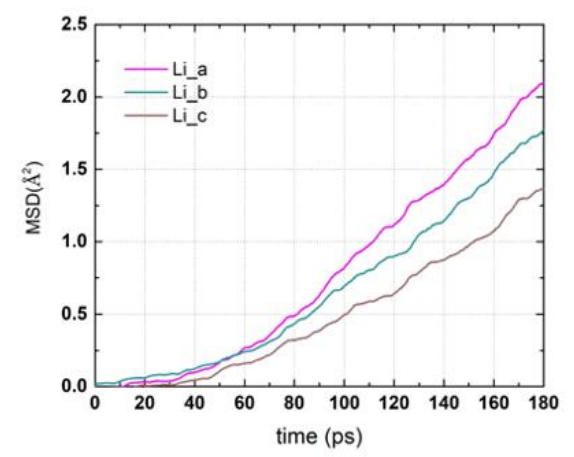

(1)

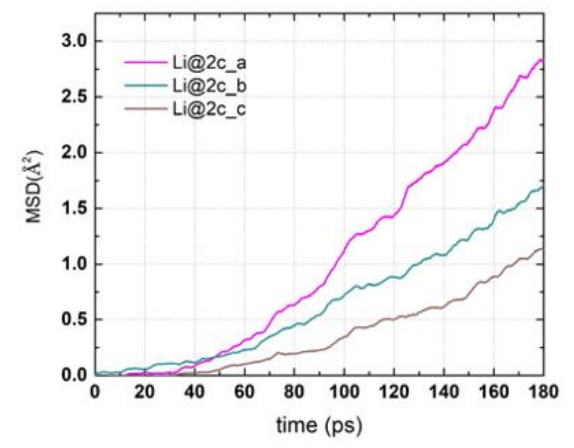

(3)

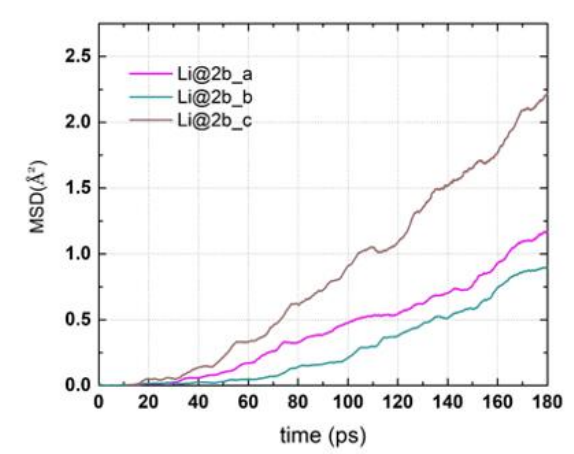

(2)

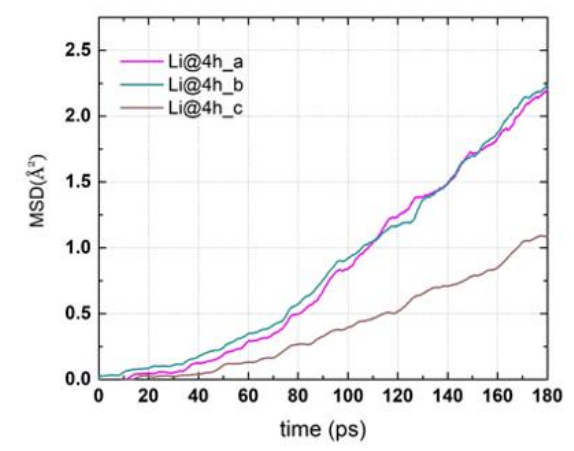

(4)

Figure 3. The MSD of $\mathrm{Li}$ ions in stoichiometric $\mathrm{Li}_{2} \mathrm{MnO}_{3}$ simulated at $1000 \mathrm{~K}$.

(1) The MSD of Li along $\mathrm{a}, \mathrm{b}$ and $\mathrm{c}$ axes as a whole. (2) The MSD of Li $\mathrm{L}_{2 \mathrm{~b}}$ along $\mathrm{a}, \mathrm{b}$ and $\mathrm{c}$ axes.

(3) The MSD of $\mathrm{Li}_{2 \mathrm{c}}$ along $\mathrm{a}, \mathrm{b}$ and $\mathrm{c}$ axes. (4) The MSD of $\mathrm{Li}_{4 \mathrm{~h}}$ along $\mathrm{a}, \mathrm{b}$ and $\mathrm{c}$ axes.

\subsection{The micro hopping path of $\mathrm{Li}$}

Once vacancies are created by the thermal vibration or external perturbation, the $\mathrm{Li}$ ions nearby tend to fill them by hopping. The nudged elastic band (NEB) method can be used to calculate the activation barriers for an ion to migrate between two sites and determine the optimum hopping path with the lowest activation barrier [29]. The NEB calculations of some cathode materials show that the hopping of Li ions may be indirect. They may pass by some metastable sites in the system and then get into the vacancies. For example, $\mathrm{Li}$ ions in $\mathrm{LiCoO}_{2}$ hop to the vacancies nearby via O-tetrahedron sites, resulting a curving hopping paths [30]. Also, the calculations of $\mathrm{LiFePO}_{4}$ show that $\mathrm{Li}$ ions move to the nearby vacancies along a zigzag path in the channels [31]. While performing an NEB calculation requires knowledge of the ion migration pathway, MD can be applied to structures that are more complex without prior assumptions about the diffusion path [32].

In this work, we studied the hopping paths of $\mathrm{Li}$ ions in stoichiometry $\mathrm{Li}_{2} \mathrm{MnO}_{3}$ by analyzing the displacement frequency distribution (DFD) of Li ions during the MD simulation. The DFD records the frequencies of displacements away from the original crystal sites of the Li ions in the system. So the domains of high frequencies indicates stable sites or metastable sites where Li ions linger for a while. To do this, the system 
was simulated for two hundred thousand time steps ( 1 fs every step) and sampled every 100 time step to count the displacements of $\mathrm{Li}_{2 \mathrm{~b}}, \mathrm{Li}_{2 \mathrm{c}}$ and $\mathrm{Li} 4 \mathrm{~h}$.

Figure 4 shows the DFD pictures of $\mathrm{Li}_{2 b}, \mathrm{Li}_{2 \mathrm{c}}$ and $\mathrm{Li}_{4 \mathrm{~h}}$ in the ab plane (To be noted, this figure just counts the Li atoms moving in the original ab plane. So if one Li ion diffuses out of the original ab plane along $\mathrm{c}$ axis, it will be ruled out in the subsequent counts). The subplot (1) clearly indicates that $\mathrm{Li}_{2 \mathrm{~b}}$ don't diffuse within the TM layer as no displacement frequencies domains exist in the outer range. This accords with the speculation from the macro diffusion of $\mathrm{Li}_{2 b}$ in the last section. The subplots (2) and (3) show the DFD pictures of $\mathrm{Li}_{2 c}$ and $\mathrm{Li}_{4 \mathrm{~h}}$ in the ab plane. As discussed above, the $\mathrm{Li}_{2} \mathrm{MnO}_{3}$ has the layered structure, consisting of layers of TM cations separated from Li layers by oxygen. In this structure, Li is coordinated octahedrally by oxygens but diffuses from site to site by hopping through intermediate tetrahedral sites. For the layered cathode materials, each tetrahedral site are coordinated by three $\mathrm{Li}$ ion in the $\mathrm{Li}$ layer and one TM ion in the TM layer. So the tetrahedral sites can all be remarked as 1$\mathrm{TM}$ channels. The energy required for a $\mathrm{Li}$ ion to cross the activated state is proved to depend on the TM ion coordinating the tetrahedral site. The DFT calculations show that low-valent TM ions are beneficial to the Li diffusion, while the high-valent TM ions bring strong electrostatic repulsion on the activated $\mathrm{Li}$ ion and hinders the diffusion [33]. For the $\mathrm{Li}_{2} \mathrm{MnO}_{3}$, the $2 \mathrm{~b}$ sites in the TM layers are occupied by Li ions, making a more complicated hopping paths for the Li ions in the Li layers. As indicated in the figure 4, the six tetrahedral sites around $\mathrm{Li}_{2 \mathrm{c}}$ can be divided into four $1-\mathrm{TM}\left(\mathrm{Mn}^{4+}\right)$ and two 0-TM channels along a axis, while the six tetrahedral sites around $\mathrm{Li}_{4 \mathrm{~h}}$ can be divided into four 1-TM $\left(\mathrm{Mn}^{4+}\right)$ and two 0-TM channels at the right/left hand side. The DFD pictures clearly show that the $\mathrm{Li}_{4 \mathrm{~h}}$ and $\mathrm{Li}_{2 \mathrm{c}}$ ions can only hopping through the 0 TM channels. The 1-TM( $\left.\mathrm{Mn}^{4+}\right)$ channels are closed for them. This accords with the calculations of DFT. The high valence state of Mn (tetravalence) brings a strong electrostatic repulsion on the activated $\mathrm{Li}$ ion and hinders the diffusion throung 1 $\mathrm{TM}\left(\mathrm{Mn}^{4+}\right)$ channels, while the 0-TM channels are always open for the diffusion.

\subsection{The delithiation mechanism}

Once Li ions are removed from the material, the periodicity of the structure is destroyed, changing the local chemical environments of the remaining Li ions. So the distribution and diffusion of $\mathrm{Li}$ ions may change in the delithiation process. This consideration is quite noticeable for $\mathrm{Li}_{2} \mathrm{MnO}_{3}$, since $\mathrm{Li}$ ions are both located at the sites in TM layer (2b) and Li layer (2c, 4h).

Several DFT works studied the delithiation process of $\mathrm{Li}_{2} \mathrm{MnO}_{3}$ by calculating the ground states of $\mathrm{Li}_{x} \mathrm{MnO}_{3}(\mathrm{x}>1)$. However, quit different results are reached. Yukinori Koyamaa et al. suggested the removal of lithium from the Li layers at the beginning of charging, then from the TM layer [16]. Ruijuan Xiao et al. pointed out that the lithium extraction from both Li (4h site) and TM ( $2 \mathrm{~b}$ site) layers starts at an even earlier stage, because the $4 \mathrm{~h}$ and $2 \mathrm{~b}$ vacancies simultaneously exist in the ground-state configuration of $\mathrm{Li}_{1.5} \mathrm{MnO}_{3}$ by their calculation[15]. However, the calculation of Eunseok Lee et al. indicates that $\mathrm{Li}$ ions at the $2 \mathrm{~b}$ site in the TM layer and $\mathrm{Li}$ at the $2 \mathrm{c}$ site in the Li layer are extracted firstly, then a fraction of the $\mathrm{Li}$ ions at the $4 \mathrm{~h}$ site in the Li layer are extracted forming a specific Li/Vac ordering, and finally all the remaining $\mathrm{Li}$ ions at $4 \mathrm{~h}$ 
site are extracted[10].

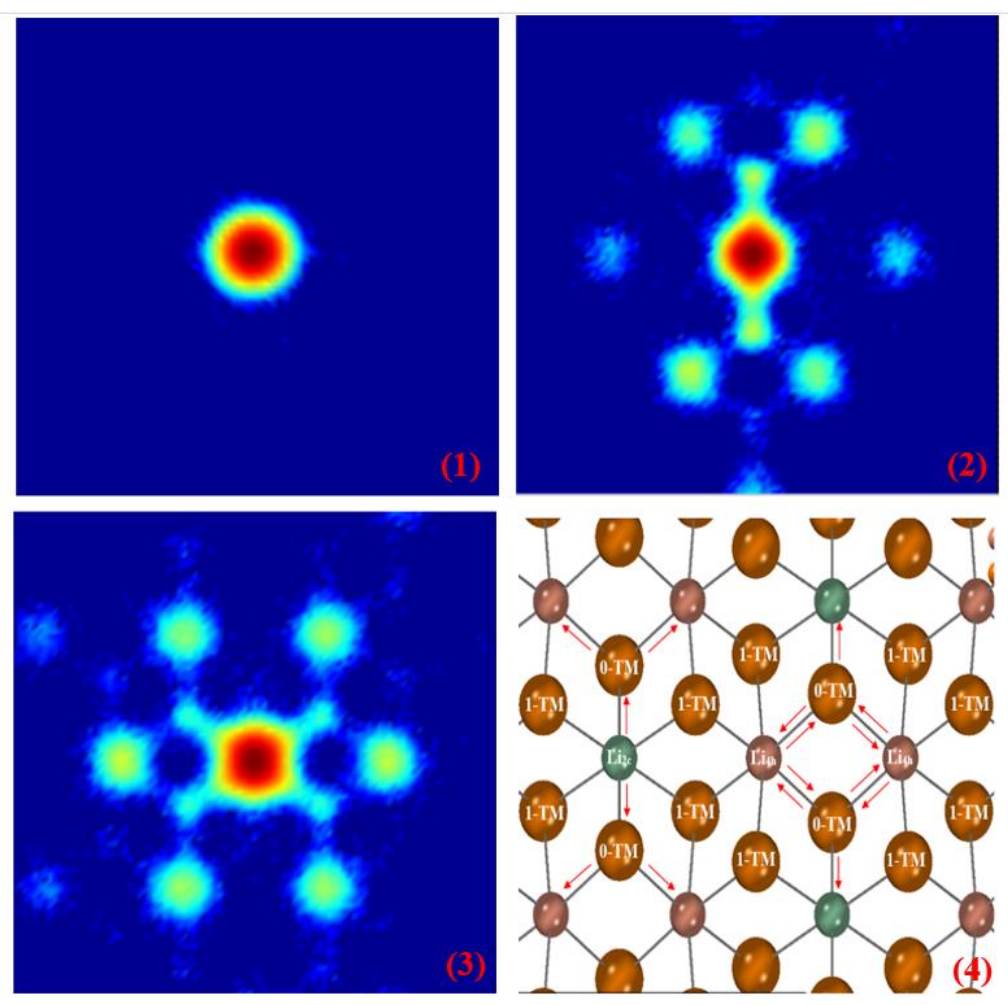

Figure 4. The displacement frequency distribution (DFD) pictures of Li ions in stiochiometry $\mathrm{Li}_{2} \mathrm{MnO}_{3}$, the range is $-5 \AA$ to $5 \AA$ along a and $\mathrm{b}$ axes. (1) The DFD picture of $\mathrm{Li}_{2 \mathrm{~b}}$. (2) The DFD picture of $\mathrm{Li}_{2 c}$. (3) The DFD picture of $\mathrm{Li}_{4 \mathrm{~h}}$. (4): A topo view of an O-Li-O inter-slab. Dark green for $\mathrm{Li}_{2 \mathrm{c}}$, dark pink for $\mathrm{Li}_{4 \mathrm{~h}}$, brown for $\mathrm{O}$. The tetrahedral sites of 0-TM and 1-TM $\left(\mathrm{Mn}^{4+}\right)$ channels and the hopping path are remarked for a better comparison with the DFD pictures.

In this article, the delithiation process of $\mathrm{Li}_{2} \mathrm{MnO}_{3}$ is investigated by MD simulation, which can probe the distribution of Li ions in the delithiated structures under the thermal equilibrium. The $\mathrm{Li}$ ions are removed randomly from the initial stoichiometry $\mathrm{Li}_{2} \mathrm{MnO}_{3}$ configuration. Then the delithiated systems were simulated at $300 \mathrm{~K}$ for 200 ps in NPT ensemble to get into the equilibrium states. We check a series of delithiated systems. The figure 5 show the MSD of $\mathrm{Li}$ in $\mathrm{Li}_{1.0} \mathrm{MnO}_{3}$ along $\mathrm{a}, \mathrm{b}$ and $\mathrm{c}$ axes. It can be inferred the three-dimensional diffusion of $\mathrm{Li}$ ions in stiochiometry $\mathrm{Li}_{2} \mathrm{MnO}_{3}$ evolves into the one-dimensional diffusion mainly along a axis in $\mathrm{Li}_{1.0} \mathrm{MnO}_{3}$. Figure 6 shows the final simulated structure of $\mathrm{Li}_{1.0} \mathrm{MnO}_{3}$. No $\mathrm{Li}$ ions remain in TM layer. In the $\mathrm{Li}$ layer, the Li ions are arranged in two sub rows on top of each other which locate at the primal rows of $\mathrm{Li}_{2 b}$ viewed from a axis. A close observation reveals that $\mathrm{Li}$ ions are in the center of $\mathrm{O}$ tetrahedrons, while the $2 \mathrm{~b}$ and $4 \mathrm{~h}$ site are at the center of $\mathrm{O}$ octahedrons. This new tetrahedral site can be set as $4 \mathrm{i}$ in Wyckoff notation. A different delithiation mechanism is inferred from our simulation. During the delithiation process, the Li ions will be driven into the tetrahedral $4 \mathrm{i}$ site by the thermodynamics, which is not predicted by DFT calculation of $\mathrm{Li}_{2} \mathrm{MnO}_{3}$. However, we can get some inspirations from the DFT calculation work of $\mathrm{LiMn}_{0.5} \mathrm{Ni}_{0.5} \mathrm{O}_{2}$ [34]. The $\mathrm{LiMn}_{0.5} \mathrm{Ni}_{0.5} \mathrm{O}_{2}$ also has a layered crystal 
structure in which Li and TM ions are separated into different layers. However, the lithium and TM ions (Ni) are not as strictly segregated. The experiments proved significant exchange of $\mathrm{Li}$ and $\mathrm{Ni}$, about $8-10 \% \mathrm{Li}$ ion residing in the TM layer and a similar amount of $\mathrm{Ni}$ in the $\mathrm{Li}$ layer. This situation resembles that of $\mathrm{Li}_{2} \mathrm{MnO}_{3}$, in both situation some $\mathrm{Li}$ ions are located in the TM layers. The replacement of TM ions by $\mathrm{Li}$ in the TM layer creates tetrahedral sites in the Li layer that are only surrounded by $\mathrm{Li}$ ions (0-TM channels). When the four face sharing octahedral sites are cleared in the delithiation process, the tetrahedral sites become stable sites and are filled by the remaining $\mathrm{Li}$ ions. For each $\mathrm{Li}$ site in the TM layer $(2 \mathrm{~b})$, there are two potential tetrahedral Li sites (4i), one above and one below. So when half of $\mathrm{Li}$ ions are removed, all the $\mathrm{Li}$ ions in $\mathrm{Li}_{1.0} \mathrm{MnO}_{3}$ will fulfill the tetrahedron $4 \mathrm{i}$ site. Then the diffusion direction of $\mathrm{Li}$ ions is mainly along a axis.

Figure 7 shows the ratios of $\mathrm{Li}$ in all the four sites $(2 \mathrm{~b}, 2 \mathrm{c}, 4 \mathrm{~h}$, tetrahedral $4 \mathrm{i}$ site) during the delithiation process. In the initial stage of delithiation $(x<0.2)$, Li ions are mainly removed from the $2 b$ site in the TM layer. At this very early stage, some Li ions have filled the $4 \mathrm{i}$ tetrahedral site. Then the Li ions are mainly remove from the $2 \mathrm{c}$ and 4h sites in the Li layer $(0.2<x<0.8)$, followed by a further fulfilling of the tetrahedral sites by Li ions. At the last stage $(x>0.8)$, the octahedral sites in the TM layer and $\mathrm{Li}$ layer are cleared simultaneously, resulting a rapid increase of $\mathrm{Li}$ ion in tetrahedron site. Finally, almost of the $\mathrm{Li}$ ions are located in the $4 \mathrm{i}$ tetrahedron site in $\mathrm{Li}_{1.0} \mathrm{MnO}_{3}$. Since the tetrahedral sites are energetically very stable, a high voltage $\left(>5.2 \mathrm{~V} \mathrm{vs}\right.$. $\left.\mathrm{Li} / \mathrm{Li}^{+}\right)$is required to remove the $\mathrm{Li}$ ions in the $4 \mathrm{i}$ site [35]. This means that almost half of the $\mathrm{Li}$ ions must be de-intercalated at the high voltage range. However, in the practical use, to keep the stabilization of liquid electrolyte, the cathodes are often cycled below $5 \mathrm{~V}$. All the experimentally measured capacities of $\mathrm{Li}_{2} \mathrm{MnO}_{3}$ samples at ambient temperature are below half of its theoretical capacity $(\sim 458 \mathrm{mAh} / \mathrm{g})[9,12,18,19,36,37,38]$, which proves our calculation. To further improve the capacity, defects in the bulk materials are introduced intentionally when synthesized $[37,38]$ or cycled at a higher temperature to increase the activity of $\mathrm{Li}$ ions $[12,17]$.

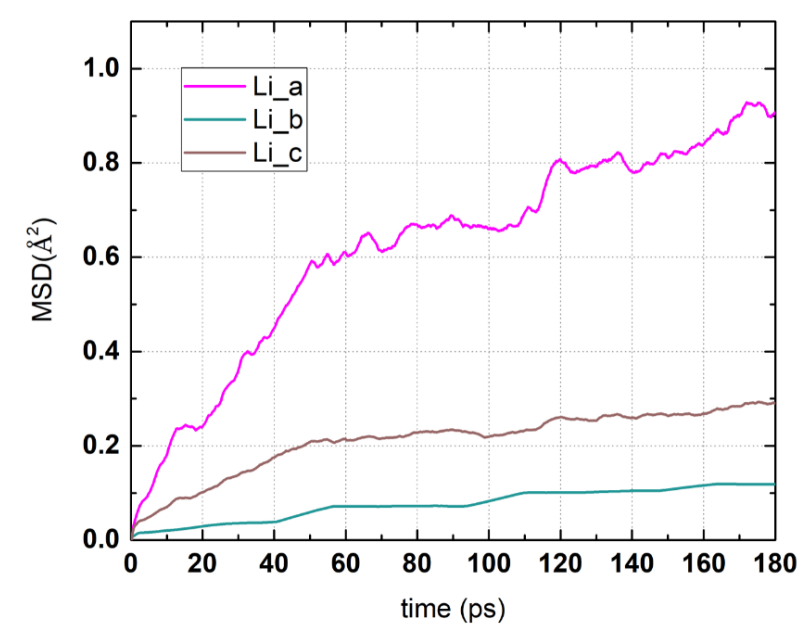

Figure 5. The MSD of Li ions in $\mathrm{Li}_{1.0} \mathrm{MnO}_{3}$ along $\mathrm{a}, \mathrm{b}$ and $\mathrm{c}$ axes 


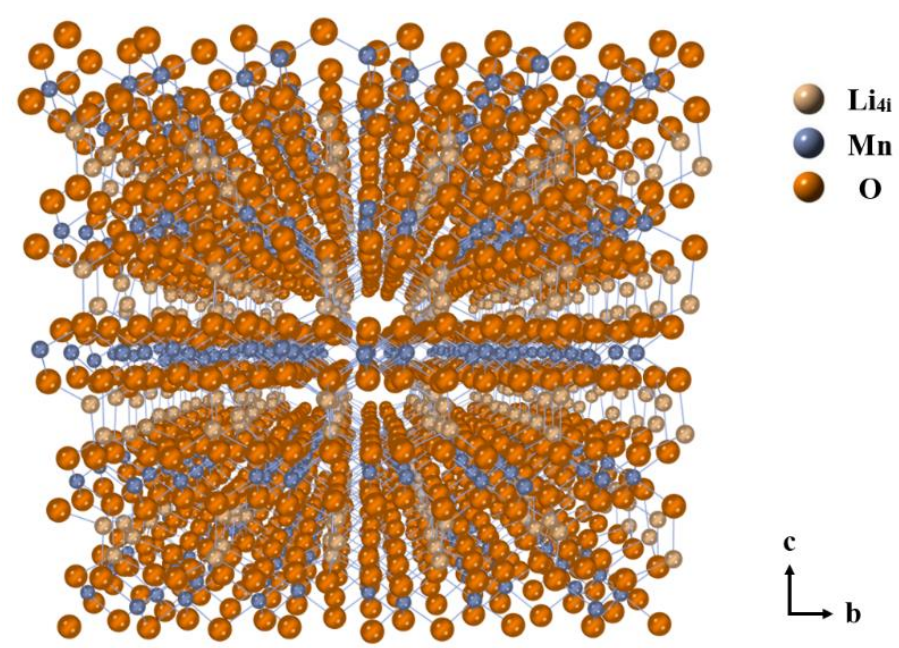

Figure 6. (1) The local picture of $\mathrm{Li}_{1.0} \mathrm{MnO}_{3}$ (viewed from a axis).

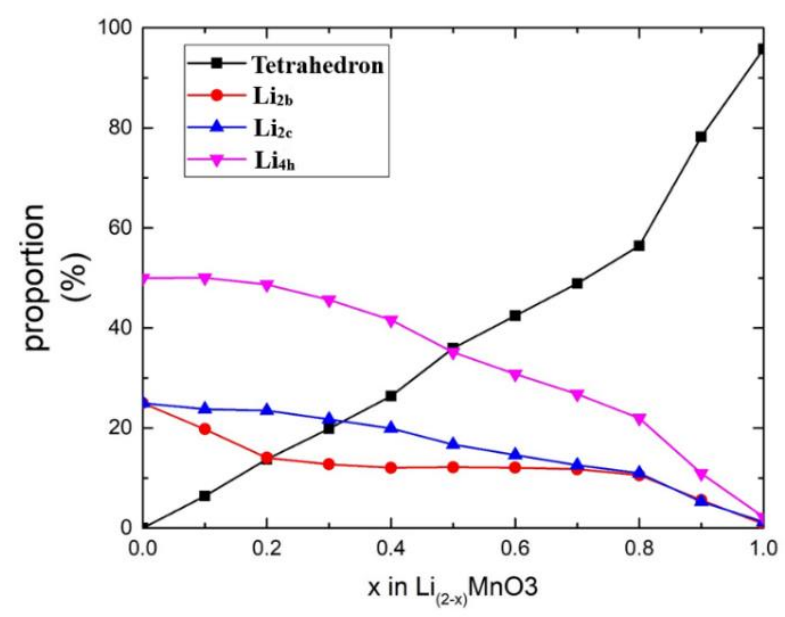

Figure 7. The proportion of $\mathrm{Li}$ ions at tetrahedron $4 \mathrm{i}$ site and octahedron $2 \mathrm{~b}, 2 \mathrm{c}$ and $4 \mathrm{~h}$ sites under the thermal dynamics equilibrium in MD simulation during the delithiation process

\subsection{The phase transformation}

Upon the further delithiation $\left(\mathrm{x}=1.2\right.$ for $\mathrm{Li}_{2-\mathrm{x}} \mathrm{MnO}_{3}$ ), we observe that some $\mathrm{Mn}$ ions migrate into the Li layer (figure 8). This indicates the possible phase transition into a spinel-like structure as discussed in many experimental and theoretical studies [10, 12, 36, 38]. In the spinel $\mathrm{LiMn}_{2} \mathrm{O}_{4}$, the $\mathrm{Li}$ ions are located at the tetrahedrons. This is also the situation for $\mathrm{Li}_{1.0} \mathrm{MnO}_{3}$ proved by last section. The major difference between the layered and spinel structures is due to the presence of octahedral Mn ions in the Li layer in the spinel structure. We carefully checked our final structure and found that most of the $\mathrm{Mn}$ ion migrating into the Li layer are located at the tetrahedrons instead of the octahedrons. This incomplete transition may be related with the Li distribution in the Li layer. In the layered structure, each octahedron site is face sharing with eight tetrahedron sites and edge sharing the other octahedron sites in the same layer or the up/down layer. With the delithiation of Li ions, the octahedral sites in the Li layer are vacant. There is a thermodynamic driving force for Mn migrating into the nearest octahedral site in the Li-layer. Like the Li ions, the migration of Mn also adopts the two step hopping [10]. The Mn ion, 1) flanked by one $\mathrm{Li}$ in the neighbouring tetrahedral 
site, migrates into the nearest tetrahedral vacancy site in the Li-layer and then 2) moves, through a face, into the nearest octahedral site in the Li layer. However, our results indicate that this process may be interrupted by step 1). The Mn ions hopping into the tetrahedrons scarcely further hop into the octahedron sites in the $\mathrm{Li}_{0 .} \mathrm{MnO}_{3}$ structure. This may be because the Li ions at the $4 \mathrm{i}$ tetrahedron site brings strong electrostatic repulsion on the face sharing octahedron sites, preventing its occupation by $\mathrm{Mn}^{4+}$. Our further check on the final structure also sustains the hypothesis. All the unoccupied octahedron sites are face sharing with Li tetrahedrons, indicating that they are 'inactive' sites for Mn ions, while several Mn octahedrons in the Li layers shares no face with the Li tetrahedrons. Our simulation shows that the phase transition may require a very deep de-intercalation of $\mathrm{Li}$ ions to accommodate the complete migration of octahedron $\mathrm{Mn}^{4+}$ in the TM layer to the octahedron vacancies in the Li layer. However, a further delithiated structure $\left(\mathrm{Li}_{0.6} \mathrm{MnO}_{3}\right)$ is unstable under the thermodynamics simulation of MD. Other process must be considered at this deep delithiation stage. To be an instinctive consideration, oxygen release should be the main factor for stabling the dynamics equilibrium at this rather high delithiation stage, as the ratios 1:3 of $\mathrm{Mn}$ to $\mathrm{O}$ in $\mathrm{Li}_{2} \mathrm{MnO}_{3}$ should be forced into 1:2 in the spinel-like structure. In fact, the oxygen release has been observed in the many electrochemical tests of $\mathrm{Li}_{2} \mathrm{MnO}_{3}$ [11-13]. Though the oxygen deficiency is often considered to be formed on the surfaces during the cycling, we believe that this phenomenon may spread to the bulk at the high delithiation stage.

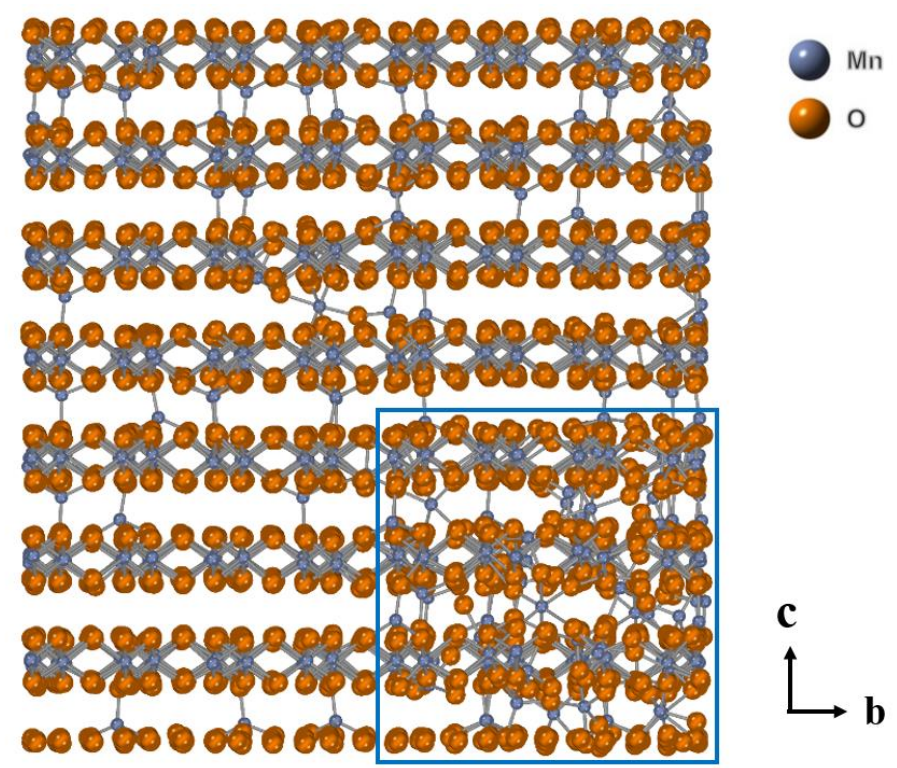

Figure 8. The final configuration of $\mathrm{Li}_{0.8} \mathrm{MnO}_{3}$. For a clear view of $\mathrm{Mn}$ arrangement, the $\mathrm{Li}$ ions are hidden. The local region inside the blue box is the main distribution zone where octahedron $\mathrm{Mn}$ ions are located. The robust oxygen framework deforms in this area, indicating the possible release of oxygen in a deep delithiation level.

\section{Conclusion}

In this article, we studied the diffusion mechanism of $\mathrm{Li}$ ions in $\mathrm{Li}_{2} \mathrm{MnO}_{3}$ and its 
delithiation process using the molecular dynamics simulation method. In order to do this work, we optimized an initial force field model established for binary oxides. The new model for $\mathrm{Li}_{2} \mathrm{MnO}_{3}$ has been validated with calculations of crystal structure and phonon dispersion curves.

Based on the new model force fields, a set of systematic MD simulations on the stiochiometry and delithiated $\mathrm{Li}_{2} \mathrm{MnO}_{3}$ have been presented. The simulations on stoichiometry $\mathrm{Li}_{2} \mathrm{MnO}_{3}$ show that the diffusion of $\mathrm{Li}$ ions is three dimensional. The $\mathrm{Li}$ sites in the TM layer open the diffusion channel along $\mathrm{c}$ aixs, which is often prohibitive in layered cathode materials. By analyzing the specific movement of $\mathrm{Li}_{2 b}$ ions in the $\mathrm{TM}$ layer and $\mathrm{Li}_{2 \mathrm{c}}, \mathrm{Li}_{4 \mathrm{~h}}$ ions in the $\mathrm{Li}$ layer, it is found that the hopping of $\mathrm{Li}_{2 b}$ within the TM layer is forbidden. The $\mathrm{O}$ (octahedron)- $\mathrm{T}$ (tetrahedron)-O(octahedron) hopping path is observed for $\mathrm{Li}_{2 \mathrm{c}}$ and $\mathrm{Li}_{4 \mathrm{~h}}$ ions in the $\mathrm{Li}$ layer. But the tetrahedral hopping channels are divided into $0-\mathrm{TM}$ and $1-\mathrm{TM}\left(\mathrm{Mn}^{4+}\right)$ subclasses. Only the 0 -TM channels are active for $\mathrm{Li}$ ions, the $1-\mathrm{TM}\left(\mathrm{Mn}^{4+}\right)$ channels are impassable as a result of the strong electrostatic repulsion.

In addition to the diffusion mechanism of $\mathrm{Li}$ ions, the delithiation process has been also simulated. We found a new delithiation mechanism, not predicted by the previous DFT works. In the delithiation process, $\mathrm{Li}$ ions remained in the system will tend to be tracked at new tetrahedron site $4 \mathrm{i}$. In the initial stage of delithiation $(\mathrm{x}<0.2), \mathrm{Li}$ ions are mainly removed from the $2 \mathrm{~b}$ site in the TM layer. Then the $\mathrm{Li}$ ions are mainly removed from the $2 \mathrm{c}$ and $4 \mathrm{~h}$ sites in the Li layer $(0.2<\mathrm{x}<0.8)$. At the last stage $(\mathrm{x}>0.8)$, the octahedral sites in the TM layer and Li layer are cleared simultaneously. The fulfilling of $4 i$ site is throughout this process, as long as a 'clean' tetrahedron site is formed with no face sharing octahedron cations. $\mathrm{Up}$ to $\mathrm{Li}_{1.0} \mathrm{MnO}_{3}$, all the $\mathrm{Li}$ ions will be located at $\mathrm{4i}$ sites and so an ordered distribution of $\mathrm{Li}$ ions is recovered. The $\mathrm{Mn}$ migration into $\mathrm{Li}$ layer is found in a $\mathrm{Li}_{0.8} \mathrm{MnO}_{3}$, indicating a phase transformation to a spinel-like structure. However, this transition is not complete, as most of Mn ions are trapped in the tetrahedral sites instead of the octahedral sites. The deeply delithiatiated structure $\left(\mathrm{Li}_{0.6} \mathrm{MnO}_{3}\right)$ is not stable during the thermodynamics process. Other charge compensation mechanism should be considered in the high delithation stage, like oxygen release et al.

Acknowledgments: This work was supported by the China Postdoctoral Science Foundation (2018M641475), the National Natural Science Funds of China (Grant No. 11605106)

\section{References}

[1] K. Mizushima, P.C. Jones, P.J. Wiseman, J.B. Goodenough. $\mathrm{LixCoO}_{2}(0<\mathrm{x} \leq 1)$ : a new cathode material for batteries of high energy density. Mat. Res. Bull., 1980, 15, 783-789.

[2] M. M. Thackeray, P. J. Johnson, L. A. De Picciotto, P. G. Bruce, J. B. Goodenough. Electrochemical extraction of lithium from $\mathrm{LiMn}_{2} \mathrm{O}_{4}$. Mater. Res. Bull., 1984, 19, 179-187.

[3] A. K. Padhi, K. S. Nanjundaswamy, J. B. Goodenough. Phospho-olivines as positive-electrode materials for rechargeable lithium batteries. J. Electrochem. Soc., 1997, 144(4), 1188-1194. 
[4] Ping He, Haoran Wang, Lu Qia, Tetsuya Osaka. Synthetic optimization of spherical $\mathrm{LiCoO}_{2}$ and precursor via uniform-phase precipitation. Journal of Power Sources. 2006, 158, 529-534.

[5] M. Stanley Whittingham. Lithium batteries and cathode materials. Chem. Rev. 2004, 104, 42714301.

[6]Jeom-Soo Kim, Christopher S. Johnson, John T. Vaughey, Michael M. Thackeray. Electrochemical and structural Properties of $x \mathrm{Li}_{2} \mathrm{M}^{\prime} \mathrm{O}_{3} \cdot(1-x) \mathrm{LiMn}_{0.5} \mathrm{Ni}_{0.5} \mathrm{O}_{2}$ electrodes for lithium batteries $\left(\mathrm{M}^{\star}=\mathrm{Ti}, \mathrm{Mn}, \mathrm{Zr} ; 0 \leq x \leqslant 0.3\right)$. Chem. Mater. 2004, 16, 1996-2006.

[7] M.M. Thackeray, S.-H. Kang, C.S. Johnson, J.T. Vaughey, S.A. Hackney. Comments on the structural complexity of lithium-rich $\mathrm{Li}_{1+\mathrm{x}} \mathrm{M}_{1-\mathrm{x}} \mathrm{O}_{2}$ electrodes $(\mathrm{M}=\mathrm{Mn}, \mathrm{Ni}, \mathrm{Co})$ for lithium batteries. Electrochemistry Communications, 2006, 8, 1531-1538.

[8] Michael M. Thackeray, Sun-Ho Kang, Christopher S. Johnson, John T. Vaughey, Roy Benedek, S. A. Hackney. $\mathrm{Li}_{2} \mathrm{MnO}_{3}$-stabilized $\mathrm{LiMO}_{2}(\mathrm{M}=\mathrm{Mn}, \mathrm{Ni}, \mathrm{Co})$ electrodes for lithium-ion batteries. J. Mater. Chem., 2007, 17, 3112-3125.

[9] C.S. Johnson, N. Li, J.T. Vaughey, S.A. Hackney, M.M. Thackeray. Lithium-manganese oxide electrodes with layered-spinel composite structures $\mathrm{xLi}_{2} \mathrm{MnO}_{3} \cdot(1-\mathrm{x}) \mathrm{Li}_{1+\mathrm{y}} \mathrm{Mn}_{2-\mathrm{y}} \mathrm{O}_{4}(0<\mathrm{x}<1$, $0 \leq y \leq 0.33$ ) for lithium batteries. Electrochemistry Communications, 2005, 7, 528-536.

[10] Eunseok Lee, Kristin A. Persson. Structural and chemical evolution of the layered li-excess $\mathrm{li}_{\mathrm{x}} \mathrm{MnO}_{3}$ as a function of li content from first-principles calculations. Adv. Energy Mater. 2014, 4, 1400498.

[11] A. Robert Armstrong, Michael Holzapfel, Petr Novak, Christopher S. Johnson, Sun-Ho Kang, Michael M. Thackeray, Peter G. Bruce. Demonstrating oxygen loss and associated structural reorganization in the lithium battery cathode $\mathrm{Li}\left[\mathrm{Ni}_{0.2} \mathrm{Li}_{0.2} \mathrm{Mn}_{0.6}\right] \mathrm{O}_{2}$. J. AM. CHEM. SOC., 2006, 128, 8694-8698.

[12] S. Francis Amalraj, Boris Markovsky, Daniel Sharon, Michael Talianker, Ella Zinigrad, Rachel Persky, Ortal Haik, Judith Grinblat, Jordan Lampert, Martin Schulz-Dobrick, Arnd Garsuchc, Luba Burlaka, Doron Aurbach. Study of the electrochemical behavior of the "inactive" $\mathrm{Li}_{2} \mathrm{MnO}_{3}$. Electrochimica Acta, 2012, 78, 32- 39.

[13] Denis Y.W. Yu, Katsunori Yanagid. Structural Analysis of $\mathrm{Li}_{2} \mathrm{MnO}_{3}$ and related Li-Mn-O materials. Journal of the Electrochemical Society, 2011, 158(9), A1015-A1022.

[14] Yasuharu Okamoto. Ambivalent effect of oxygen vacancies on $\mathrm{Li}_{2} \mathrm{MnO}_{3}$ : a first-principles study. Journal of the Electrochemical Society, 2012, 159(2), A152-A157.

[15] Ruijuan Xiao, Hong Li, Liquan Chen. Density functional investigation on $\mathrm{Li}_{2} \mathrm{MnO}_{3}$. Chem. Mater. 2012, 24, 4242-4251.

[16] Yukinori Koyama, Isao Tanaka, Miki Nagao, Ryoji Kanno. First-principles study on lithium removal from $\mathrm{Li}_{2} \mathrm{MnO}_{3}$. Journal of Power Sources, 2009, 189, 798-801.

[17] Alastair D. Robertson, Peter G. Bruce. The origin of electrochemical activity in $\mathrm{Li}_{2} \mathrm{MnO}_{3}$. CHEM. COMMUN. , 2002, 2790-2791.

[18] Alastair D. Robertson, Peter G. Bruce. Mechanism of electrochemical activity in $\mathrm{Li}_{2} \mathrm{MnO}_{3}$. Chem. Mater. 2003, 15, 1984-1992.

[19] Younkee Paik, Clare P. Grey, Christopher S. Johnson, Jeom-Soo Kim, Michael M. Thackeray. Lithium and deuterium NMR studies of acid-leached layered lithium manganese oxides. Chem. Mater. 2002, 14, 5109-5115.

[20] Alfonso Pedone, Gianluca Malavasi, M. Cristina Menziani, Alastair N. Cormack, Ulderico Segre. A new self-consistent empirical interatomic potential model for oxides, silicates, and silica- 
based glasses. J. Phys. Chem. B., 2006, 110, 11780-11795.

[21] Gale, Julian, Rohl, Andrew. The general utility lattice program (GULP). Molecular Simulation. 2003, 29(5), 291-341.

[22] Pierre Strobel, Bernadette Lambert-Andron. Crystallographic and Magnetic Structure of $\mathrm{Li}_{2} \mathrm{MnO}_{3}$. Journal of solid state chemistry, 1988, 75, 90-98.

[23] Atsushi Togo, Isao Tanaka. First principles phonon calculations in materials science. Scripta Materialia, 2015, 108, 1-5.

[24] Ilian T. Todorov, William Smith, Kostya Trachenko, Martin T. Dove. DL_POLY_3: new dimensions in molecular dynamics simulations via massive parallelism. J. Mater. Chem., 2006, 16, 1911-1918.

[25] L. Verlet, Computer "Experiments" on Classical Fluids. I. Thermodynamical Properties of Lennard-Jones Molecules. Phys. Rev., 1967, 159, 98-103.

[26] P. P. Ewald. Die Berechnung optischer und elektrostatischer Gitterpotentiale. Ann. Phys., 64, 1921, 253-287.

[27] S. Nose, A unified formulation of the constant temperature molecular dynamics methods, J. Chem. Phys., 1984, 81, 511-519.

[28] W. G. Hoover, Canonical dynamics: Equilibrium phase-space distributions. Phys. Rev. A, 1985, 31(3), 1695-1697.

[29] Yan Wang, William Davidson Richards, Shyue Ping Ong, Lincoln J. Miara, Jae Chul Kim, Yifei Mo, Gerbrand Ceder. Design principles for solid-state lithium superionic conductors. NATURE MATERIALS, 2015, 14, 2016-1031.

[30] A. Van der Ven, G. Ceder. First-principles theory of ionic diffusion with nondilute carriers. PHYSICAL REVIEW B, 2001, 64, 184307.

[31] M. Saiful Islam, Daniel J. Driscoll, Craig A. J. Fisher, Peter R. Slater. Atomic-scale investigation of defects, dopants, and lithium transport in the lifepo4 olivine-type battery material. Chem. Mater. 2005, 17, 5085-5092.

[32] Gerbrand Ceder, Shyue Ping Ong, Yan Wang. Predictive modeling and design rules for solid electrolytes. Frontiers of Solid-State Batteries, 2018, 43(10), 746-751.

[33] Kisuk Kang, Ying Shirley Meng, Julien Bre'ger, Clare P. Grey, Gerbrand Ceder. Electrodes with high power and high capacity for rechargeable lithium batteries. Scienec, 2006, 311, 977-980. [34] A. Van der Ven, G. Ceder. Ordering in $\mathrm{Li}_{\mathrm{x}}\left(\mathrm{Ni}_{0.5} \mathrm{Mn}_{0.5}\right) \mathrm{O}_{2}$ and its relation to charge capacity and electrochemical behavior in rechargeable lithium batteries. Electrochemistry Communi- cations, 2004, 6, 1045-1050.

[35] Julien Breger, Ying. Meng, Yoyo Hinuma, Sundeep Kumar, Kisuk Kang, Yang Shao-Horn, Gerbrand Ceder, Clare P. Grey. Effect of High Voltage on the Structure and Electrochemistry of $\mathrm{LiNi}_{0.5} \mathrm{Mn}_{0.5} \mathrm{O}_{2}$ : A Joint Experimental and Theoretical Study. Chem. Mater.2006, 18, 20, 4768-4781.

[36] Sang-Ho Park, Yuichi Sato, Jae-KooK Kim, Yun-Sung Lee. Powder property and electrochemical characterization of $\mathrm{Li}_{2} \mathrm{MnO}_{3}$ material. Materials Chemistry and Physics, 2007, 102, 225-230.

[37] Rui Wang, Xiaoqing He, Lunhua He, Fangwei Wang, Ruijuan Xiao, Lin Gu, Hong Li, Liquan Chen. Atomicstructure of $\mathrm{Li}_{2} \mathrm{MnO}_{3}$ after partial delithiation and re-lithiation. Adv. Energy Mater. 2013, 3, 1358-1367.

[38] Denis Y. W. Yu, Katsunori Yanagida, Yoshio Kato, Hiroshi Nakamura. Electrochemical Activities in $\mathrm{Li}_{2} \mathrm{MnO}_{3}$. Journal of the electrochemical society, 2009, 156(6), A417-A424 